\title{
Analisa Efektifitas Perbaikan Perangkat BTS Telkomsel Karawang dengan iManager u2000 software
}

\author{
Felyta Emasriani ${ }^{1}$ Reni Rahmadewi ${ }^{2}$ \\ ${ }^{1}$ Fakultas Teknik,Universitas Singaperbangsa Karawang \\ e-mail: felyta.emasriani17054@student.unsika.ac.id ${ }^{1}$ reni.rahmadewi@ft.unsika.ac.id ${ }^{2}$
}

\section{ARTICLE INFO}

Article history:

Received 30 Mei 2020

Received in revised form 2 Juni 2020

Accepted 10 Juni 2020

Available online 12 Juni 2020

\section{ABSTRACT}

Recently, the need for cellular telecommunication services in Indonesia refers to a very large number. This customer growth rate must be balanced with infrastructure development. PT. Telkomsel carries out scheduled maintenance or maintenance activities on BTS devices. Based on these problems, the research carried out by the author aims to find out and understand the repair or repair procedures on computerized BTS devices at PT. Telkomsel, Karawang. The result of the research is that it is known that the application of a computerized system at PT. Telekomunikasi Selular GraPaRi Karawang helps the process of repairing BTS devices in meeting information needs. To monitor damage to BTS equipment, it is done by means of an alarm monitoring system using the iManager u2000 software.

Keywords: Repairment, BTS, Telkomsel

\section{Pendahuluan}

Dalam gaya hidup modern yang selalu terhubung, hampir semua orang membawa perangkat komunikasi seluler, seperti telepon konvensional atau ponsel pintar. Adopsi besarbesaran perangkat layanan seluler ini menunjukkan bahwa kompleksitas baru yang terkait dengan sosial, keamanan, dan etiket telah muncul di area di mana keheningan diharapkan atau bahkan wajib, seperti di sekolah, universitas, tempat ibadah, dan rumah sakit. Di beberapa lingkungan, penggunaan ponsel tidak diinginkan, seperti ruang pertemuan, tempat ibadah, dan rumah sakit, sedangkan penggunaannya di area sensitif keamanan harus dikontrol sesuai dengan rencana keamanan.[1] Dalam jaringan komunikasi nirkabel, penting untuk menjadwalkan transmisi sesuai dengan prioritas yang berbeda dari paket data yang berbeda. Cukup sering, penjadwalan dilakukan dengan cara terdistribusi dan pertukaran informasi melalui saluran nirkabel diperlukan. [2]

Komunikasi sangat penting untuk pekerjaan terdistribusi [3], tetapi agar efektif, komunikasi harus beradaptasi dengan perubahan hubungan antara kolaborator, perubahan dalam tugas pekerjaan yang mereka lakukan, dan perubahan dalam konteks di mana komunikasi itu digunakan. [4]. Kebutuhan komunikasi berkecepatan tinggi dan berkapasitas besar dalam bidang telekomunikasi saat ini sangat besar dan mendukung perkembangan teknologi informasi yang semakin berkembang di era masyarakat modern ini. Kemajuan perekonomian serta berkembangnya teknologi telekomunikasi merupakan titik tolak dan potensi besar untuk dapat meningkatkan dan mewujudkan berbagai jenis pelayanan komunikasi yang lebih canggih dengan akses yang cepat dan murah. [5] 
Dalam menunjang kegiatan komunikasi tersebut maka diperlukan sarana perantara yang dapat menghubungkan pengguna salah satunya adalah telekomunikasi seluler. Akhir-akhir ini kebutuhan terhadap jasa telekomunikasi seluler di Indonesia merujuk pada angka yang terbilang sangat besar. Dalam bidang bisnis telekomunikasi seluler, angka pertumbuhan pelanggan harus bisa diimbangi dengan pembangunan infrastrukturnya. Salah satu contoh perusahaan provider yang melakukan hal tersebut adalah PT. Telkomsel. Ketatnya persaingan dalam dunia telekomunikasi serta banyaknya pemain baru dalam bidang jaringan telekomunikasi, maka PT. Telkomsel sebagai salah satu operator sistem telekomunikasi yang telah dikenal luas didunia internasional, yang memfokuskan diri dalam teknologi telekomunikasi harus jeli dalam melihat situasi dan kondisi saat ini, karena pada saat ini banyak perusahaan khususnya dalam bidang telekomunikasi yang ingin mempromosikan produk, pelayanan dan menyampaikan informasi tentang perusahaan mereka seluas-luasnya [6]

PT.Telkomsel memiliki cara tersendiri dalam mengimbangi antara kebutuhan pelanggan dengan pembangunan infrastruktur, yaitu dengan membangun Base Transceiver Station atau disingkat BTS. Tentunya solusi penambahan jumlah BTS ini memiliki sisi negatif bagi PT. Telkomsel yaitu diantaranya bisa mengakibatkan PT. Telkomsel kehilangan revenue atau loss profit apabila BTS pada perusahaan mengalami kerusakan atau gangguan akibat dari pemakaian yang terus-menerus. BTS merupakan infrastruktur yang sangat penting untuk Telkomsel [7] .

PT Telkomsel Indonesia adalah salah satu perusahaan penyedia jasa telekomunikasi yang mempunyai pelanggan sekitar 131,5 juta dan menguasai sekitar $49 \%$ pangsa pasar jasa telekomunikasi seluler. Salah satu infrastruktur penting dalam mendukung kegiatan operasional operator seluler adalah Base Transceiver Station (BTS). Apabila BTS mengalami kerusakan sehingga terjadi BTS down, maka dapat menimbulkan konsekwensi yang serius terhadap potential revenue dan mengakibatkan loss profit dan berimbas pada ketidakpuasan konsumen PT. Telkomsel [8])

Untuk mengurangi nilai loss profit tadi, PT. Telkomsel melakukan kegiatan maintenance atau perawatan terjadwal pada perangkat BTS, guna menjaga BTS tersebut bekerja dengan baik sesuai fungsinya. Berdasarkan permasalahan tersebut, maka penelitain ini dilakukan untuk mengetahui serta memahami prosedur perbaikan atau repair pada perangkat BTS di PT. Telkomsel, Karawang.

BTS (Base Transceiver Station) adalah sebuah perangkat yang berfungsi menghubungkan atau menjembatani perangkat komunikasi jaringan pengguna seluler menuju jaringan lainnya. BTS-BTS yang terhubung kemudian dikontrol oleh suatu perangkat yang disebut dengan BSC atau Base Station Controller, [9] perangkat ini dihubungkan dengan koneksi serat optik ataupun microwave. BSC biasanya adalah sebuah discrete unit yang tergabung dalam TRX dalam perangkat compact BTS..Base Station terdiri dari subsistem multiple base station transceiver (BTS), sebuah kontrol stasiun dasar atau BSC (Base Station Controller) dan manager stasiun dasar atau BSM (Base Station Manager) ([10]. BTS merupakan penghubung jaringan suatu operator telekomunikasi seluler dengan konsumennya. BTS terdiri dari tiga bagian utama, yaitu: Tower, Shelter, dan Feeder [11].

Kesamaan antara handphone dan BTS adalah keduanya disebut transceiver karena sifat keduanya yang sama-sama dapat mengirimkan serta menerima informasi sekaligus. Sehingga pada saat handphone mengirimkan suatu informasi pada BTS, saat itu pun BTS juga dapat mengirimkan suatu informasi kepada handphone dengan bersama-sama seperti saat kedua pelanggan mengobrol lewat handphone berkomunikasi dua arah, keduanya dapat mengobrol berbarengan. Topologi BTS ditunjukkan oleh Gambar 1 


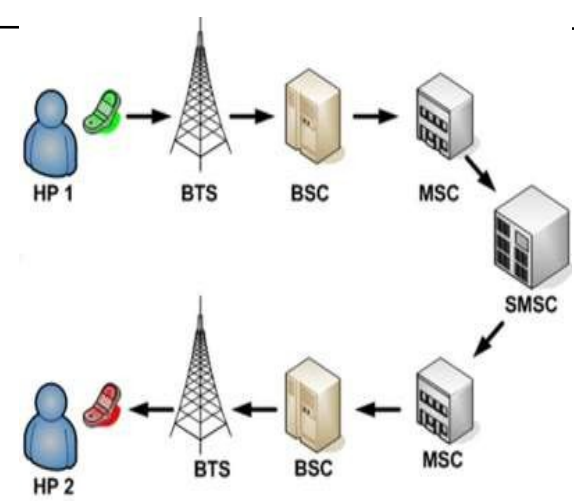

Gambar 1. Topologi BTS

Seperti yang dapat dilihat pada gambar 1, fungsi dari BTS yaitu sebagai interface untuk providing jaringan, jaringan ini berupa sinyal radio gelombang elektromagnetik untuk penggunanya, contohnya seperti modem, telepon/handphone, faxmail, dll.

Arah komunikasi yang berasal dari BTS menuju pengguna disebut dengan downlink, adapun untuk arah sebaliknya disebut dengan uplink [12] seperti yang ditunjukkan oleh gambar 2.

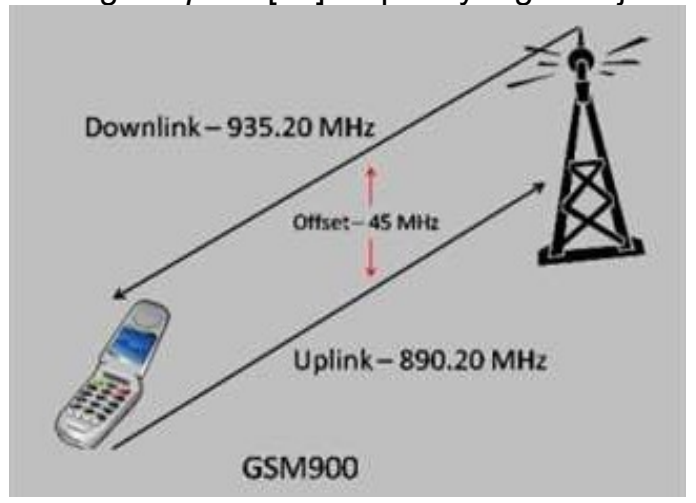

Gambar 2. Downlink dan Uplink

BTS memiliki beberapa komponen, berikut akan dijelaskan beberapa komponen yang terdapat dalam perangkat BTS yaitu (1) Tower, dan (2) Shelter. Tower merupakan komponen wajib dari perangkat BTS sebagai sarana komunikasi dan informasi yang berfungsi untuk tempat antenna dan radio baik transmitter atau pemancar maupun receiver atau penerima gelombang telekomunikasi dan informasi dipasang. Tower BTS ditunjukkan oleh gambar 3.

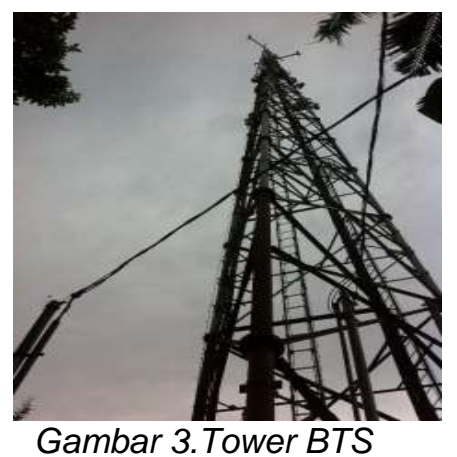

Tower BTS memiliki beberapa tipe berdasarkan konstruksinya yaitu tower berkaki 4 , tower segitiga dan tower dengan pipa besi. Dalam tower BTS terdapat beberapa komponen antenna sektoral, antenna microwave, penangkal petir, dan lampu. Shelter BTS merupakan suatu tempat yang berfungsi untuk menyimpan device telekomunikasi yang terletak di dekat tower karena baik tower maupun shelter saling ketergantungan. Shelter adalah media penyimpan 
instrumen yang akan terkoneksi dengan sentral device. Dalam suatu shelter terdapat RBS 3G dan 2G, 1 RBS memiliki 6 TRU, dalam 1 TRU terdapat 2TRx. Komponen yang terdapat pada shelter BTS antara lain transmitter, rectifier, air conditioner, power distribution board (PDB), lampu, power distribution box dan grounding

\section{Metode Penelitian}

Metode penelitian yang dilakukan adalah metode penelitian eksperimen, dimana tahapan-tahapan yang dilakukan adalah meliputi pengumpulan data, analisa sistem, prosedur, dan pengujian.Metode penelitian eksperimental adalah konsep dasar sebuah percobaan yang dilakukan untuk mengontrol atau menentukan efek dari satu variabel atau lebih [13]. Lokasi penelitian ini yaitu PT. Telkomsel Karawang. Pengumpulan data dilakukan dengan memperoleh data yang relevan, mengintegrasikan semua data kedalam set. Kemudian penelitian dilakukan dengan mengumpulkan penelitian terdahulu yang terkait dengan topik pembahasan penelitian yaitu BTS. Penelitian dilakukan dengan cara pengujian prosedur perbaikan yang diuji untuk mengetahui keberhasilan dalam mengurangi potensi kerugian dari PT. Telkomsel. Adapun prosedur yang dijalankan termasuk Prosedur Monitoring Alarm, Prosedur Proses Analisa OTT (Open Trouble Ticket), Prosedur Proses Analisa Perangkat Mati. Setelah ketiga prosedur itu dijalankan maka akan diperoleh hasil penelitian dan peneliti dapat menarik kesimpulan

\section{Hasil dan Pembahasan}

Dengan perkembangan teknologi yang semakin maju, sekarang ini banyak sekali perusahaan-perusahaan swasta yang berkembang yang bergerak dibidang ekonomi maupun jasa. Salah satu perusahaan yang bergerak dibidang jasa adalah Perbaikan perangkat Telkomsel. Dengan adanya Perbaikan perangkat Telkomsel ini akan memperbaiki kualitas signal tidak stabil menjadi baik agar para konsumen nyaman dalam berkomunikasi.

Untuk mengolah perusahaan dengan baik dan optimal, terutama terhadap sumber daya manusia, perusahaan menerapkan manajemen yang dituangkan dalam bentuk struktur organisasi. Terdapat beberapa posisi dalam struktur organisasi NS Telkomsel Karawang yaitu:

a. Head of RAN Karawang

b. TA RAN Karawang 1

c. TA RAN Karawang 2

d. Admin RAN Karawang

e. Engineer RAN Karawang 1

f. Engineer RAN Karawang 2

\section{Prosedur Perbaikan Perangkat}

Berikut merupakan prosedur perbaikan perangkat BTS Telkomsel yaitu:

a. Prosedur Monitoring Alarm

External Alarm Status atau disingkat dengan EAS merupakan sebuah alarm yang digunakan untuk mengindikasikan bahwa suatu RBS mengalami gangguan atau tidak. [14]Software yang digunakan TA RAN untuk memonitoring perangkat BTS adalah iManager 42000 . Berikut ini adalah tampilan dari software iManageru2000.

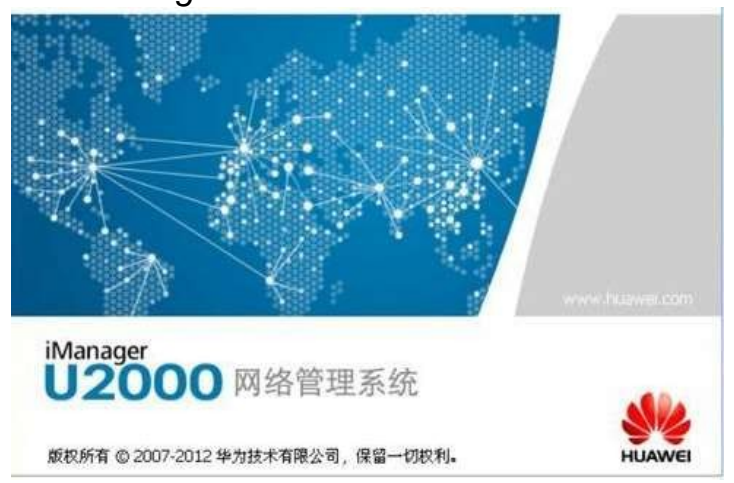

Gambar 4. Tampilan software iManager U2000 


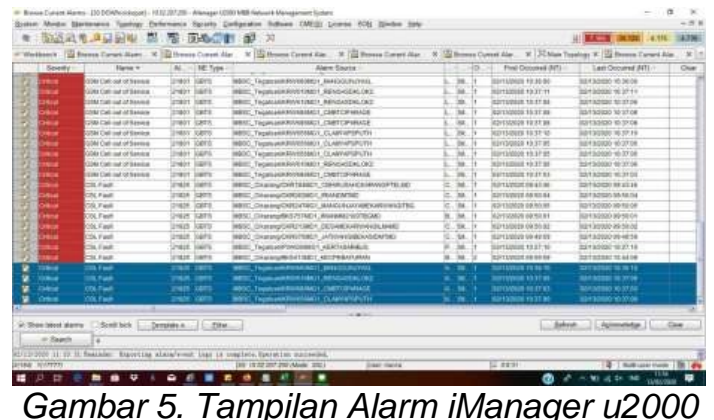

a. Prosedur Proses Analisa OTT (Open Trouble Ticket)

Operation Maintenance Servis (OMC) mengeluarkan Number Trouble Ticket (TT). OMC ini bertujuan untuk membantu proses penanganan dan administrasi yang efesien dan tersentral dari sebuah sistem seperti BTS [15]. Proses TT ini di keluarkan karena terlihat adanya perangkat BTS Telkomsel yang sedang mati (off) pada alarm. Dengan adanya TT ini durasi Time Off nya dapat diketahui oleh seluruh atasan dan staff yang bekerja di bagian area tersebut. TT tersebut dan surat izin masuk ke site dibagikan dan diinformasikan keseluruh operator enginer masing- masing agar segera ditangani perangkat yang sedang mati.

b. Prosedur Proses Analisa Perangkat Mati

Setelah proses TT serta surat izin masuk ke site dikeluarkan dan telah sampai ke pihak area yang bersangkutan, langkah selanjutnya proses analisa perangkat yang rusak yang menyebabkan BTS mati. Langkah pertama lalukan pengecekan kelistrikan (PLN) aman atau tidak nya dari tegangan listrik. Jika arus listrik normal lanjut pengecekan di sisi perangkat cek satupersatu module apakah ada yang rusak atau tidak jika di dapat ada perangkat yang rusak segera lakukan pergantian.

Jenis-jenis Penanganan Gangguan

Berikut merupakan tampilan dari jenis-jenis penanganan gangguan pada perangkat BTS Telkomsel ditunjukan pada tabel 1.

\begin{tabular}{|c|c|c|}
\hline No & Gangguan & Cara Penanganannya \\
\hline 1 & $\begin{array}{l}\text { Baterai } \\
\text { up apak mampu mem-back } \\
\text { pemadaman listrik. }\end{array}$ & $\begin{array}{l}\text { Mengganti ulang baterai yang digunakan oleh } \\
\text { RBS. }\end{array}$ \\
\hline 2 & Baterai hilang dicuri. & Menambahkan baterai \\
\hline 3 & $\begin{array}{l}\text { Terjadi kerusakan pada module } \\
\text { yang terdapat pada RBS. }\end{array}$ & $\begin{array}{l}\text { Melakukan restart RBS, jika masih terdapat } \\
\text { kesalahan maka } \\
\text { ganti board yang bermasalah. }\end{array}$ \\
\hline 4 & $\begin{array}{l}\text { Adanya kebocoran sinyal di } \\
\text { bagian feeder antenna sectoral } \\
\text { yang dapat menyebabkan } \\
\text { RBSbad } \\
\text { performance. }\end{array}$ & $\begin{array}{l}\text { Memeriksa VSWR antena sektoral melalui jumper } \\
\text { kabel feeder dengan anritsu. }\end{array}$ \\
\hline 5 & $\begin{array}{l}\text { RBS down atau out of service, } \\
\text { dengan kata lain RBS tidak dapat } \\
\text { memancarkan sinyal ke BSC } \\
\text { atau ke RBS lain. }\end{array}$ & $\begin{array}{l}\text { Periksa pada bagian transmisi apakah ada link } \\
\text { yang terputus, jika memang link transmisi yang } \\
\text { terputus kemudian periksa lagi } \\
\text { apakah ada Hub yang terputus. }\end{array}$ \\
\hline 6 & $\begin{array}{c}\text { Temperatur di } \\
\text { shelter terlalu tinggi. }\end{array}$ & $\begin{array}{l}\text { Menurunkan suhu ruangan shelter } \\
\text { menjaganya agar tetap stabil. }\end{array}$ \\
\hline 7 & $\begin{array}{l}\text { Ada genangan air disekitar } \\
\text { lingkungan RBS. }\end{array}$ & $\begin{array}{l}\text { Mengunjungi lokasi dan } \\
\text { Membersihkan setiap genangan yang ada di } \\
\text { lingkungan RBS. }\end{array}$ \\
\hline
\end{tabular}




\begin{tabular}{|c|c|c|}
\hline & $\begin{array}{l}\text { AL ILMIAH ELEKTRONIKA DAN } \\
\text { ISSN : 1907-0012 (print) } \\
\text { ISSN : } 2714-5417 \text { (online) } \\
\end{array}$ & OMPUTER, Vol.14, No.1, Juli 2021, pp. $114-120$ \\
\hline 8 & $\begin{array}{l}\text { Jumlah dari slip frame yang } \\
\text { dihasilkan melebihi ambang. }\end{array}$ & $\begin{array}{l}\text { Saluran transmisi untuk RBS harus dikonfigurasi } \\
\text { ulang. }\end{array}$ \\
\hline 9 & $\begin{array}{l}\text { Peer equipment tidak tersedia } \\
\text { sehingga saluran menjadi } \\
\text { terputus. }\end{array}$ & $\begin{array}{l}\text { Batalkan mode loopback dalam peer equipment } \\
\text { serta memeriksa apakah jalur transmisi RBS } \\
\text { sudah dalam kondisi yang benar. }\end{array}$ \\
\hline 10 & $\begin{array}{l}\text { Lokasi permulaan dari frame } \\
\text { tidak dapat ditunjukkan. }\end{array}$ & 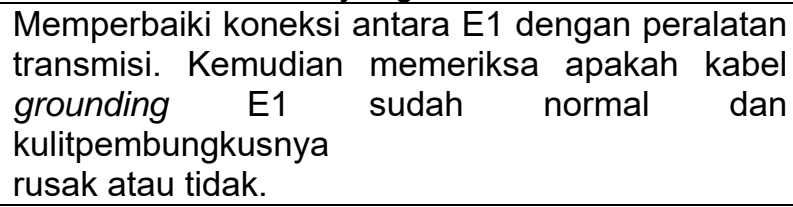 \\
\hline 11 & $\begin{array}{l}\text { Tidak ada sinyal pada masukan } \\
\text { sehingga layanan pada saluran } \\
\text { A- interface -kan terputus. }\end{array}$ & $\begin{array}{l}\text { Memperbaiki transmisi dari saluran } A \text {-interface } \\
\text { yaitu antarmuka yang menangani BSS } \\
\text { dengan MSC. }\end{array}$ \\
\hline 12 & $\begin{array}{l}\text { Pada sisi Tx dalam keadaan LOF } \\
\text { (Loss of Frame) atau LOS } \\
\text { (Lossof Signal). Sehingga } \\
\text { menyebabkan pengiriman sinyal } \\
\text { dalam } A-\text { interface menjadi } \\
\text { terputus. }\end{array}$ & $\begin{array}{l}\text { Hampir sama dengan jenis alarm E1/T1 LOS } \\
\text { (loss of signal)cara penanganannya yaitu } \\
\text { dengan menangani kesalahan pada rangkaian } \\
\text { penerima serta jalur } \\
\text { transmisi. }\end{array}$ \\
\hline
\end{tabular}

\section{Kesimpulan}

Berdasarkan hasil penelitian maka kesimpulan yang diperoleh adalah bahwa penerapan sistem komputerisasi pada PT.Telekomunikasi Selular GraPaRi Karawang membantu proses perbaikan perangkat BTS dalam memenuhi kebutuhan informasi. Untuk memantau kerusakan pada perangkat BTS dilakukan dengan cara sistem monitoring alarm dengan menggunakan software iManageru2000.

Adapun rekomendasi dari penelitian ini yaitu agar dilakukan penambahan karyawan dibagian Engineer RAN Karawang karena minimnya karyawan sehingga memperlambatpekerjaan apabila banyak site-site yang ada di RAN Karawangmati. Selain itu agar meningkatkan komunikasi pada saat perbaikan perangkat BTS agar proses perbaikan tidak memakan waktu yang lama.

\section{Daftar Pustaka}

[1] Behairy, H., Alrobian, W., Alghammas, A., Alasaad, A., Suter, B., Alshareef, M., \& Alsuwayyeh, Y. (2015). Selective Mobile Communication within a Coverage Area Bounded by Radiating Cables. Mobile Information Systems. https://doi.org/10.1155/2015/138067

[2] H. Li and J. B. Song, "Communication Complexity of Distributed Scheduling in Wireless Communication Networks," in IEEE Communications Letters, vol. 17, no. 7, pp. 1368-1371, July 2013, doi: 10.1109/LCOMM.2013.052013.130405.

[3] G. DeSanctis, M. Wright, and L. Jiang, "Building a global learning community," Commun. ACM, vol. 44, no. 12, pp. 80-83, 2001.

[4] C. B. Gibson and J. L. Gibbs, "Unpacking the concept of virtuality: The effects of geographic dispersion, electronic dependence, dynamic structure, and national diversity on team innovation," Admin. Sci. Quart., vol. 51, pp. 451-495, 2006

[5] Praja FG, Aryanta DW, Lidyawati L. Analisis Perhitungan dan Pengukuran Transmisi Jaringan Serat Optik Telkomsel Regional Jawa Tengah. REKA ELKOMIKA. 2013;1(1).

[6] Yan P, Permasi (2007) ANALISIS SISTEM JARINGAN PT. TELKOMSEL DI AREA NETWORK OPERASI BEKASI. Unikom. 
p-ISSN : 1907-0012 (print)

e-ISSN : $2714-5417$ (online)

[7] Retnosarl, D., \& Setiadi, B. (2018). IMPLEMENTAST MONITORING BASE TRANSCEIVER STATION SYSTEM (BTS) BERBASIS WEB. Technologia: Jurnal IImiah. https://doi.org/10.31602/tji.v9i2.1375

[8] Anggriawan, A., Saedudin, R. R., \& Kurniawati, A. (2015). OPTIMALISASI UMUR BTS, JUMLAH MAINTENANCE SITE CREW DAN PENENTUAN BIAYA MAINTENANCE DENGAN MENGGUNAKAN METODE LIFE CYCLE COST (STUDI KASUS: PT TELKOMSEL INDONESIA). Jurnal Rekayasa Sistem \& Industri (JRSI). https://doi.org/10.25124/jirsi.v2i03.62

[9] Lyu DS, Hong JH, Jang MS, Shin DJ, Lee CK, Lee H. An Implementation of Transcoding/Selecting System in Base Station Controller for Digital Cellular Communication. InISITA'94: International Symposium on Information Theory \& Its Applications 1994; Proceedings 1994 (p. 505). Institution of Engineers, Australia.

[10] Ahn, J. H., Shin, D. J., \& Cho, C. H. (1997). Development of the base station controller and manager in the CDMA mobile system. ETRI Journal. https://doi.org/10.4218/etrii.97.0197.0304

[11] Siregar, M. I. S., Suwarno, S., \& Putri, S. M. (2019). Perancangan Peralatan Sistem Keamanan Elektronik di SHELTER BTS Secara Real Time Melalui SMS Berbasis MIKROKONTROLLER ATMega16 dan Module GSM. JOURNAL OF ELECTRICAL AND SYSTEM CONTROL ENGINEERING. https://doi.org/10.31289/jesce.v2i2.2357

[12] Andriancoko, A. (2011). Analisis Perancangan Jaringan GSM-R (Global System for Mobile Communication-Railway) untuk Komunikasi Train Dispatching di Koridor Jakarta-Bandung. Perorangan

[13] Prasetyo, M. S., Akbar, A., \& Istiqlaliyah, H. (2020). Analisa Heat Transfer Alat Pasteurisasi Susu. Jurnal Mesin Nusantara. https://doi.org/10.29407/jmn.v3i1.14217

[14] Liu J, Lim KW, Ho WK, Tan KC, Srinivasan R, Tay A. The intelligent alarm management system. IEEE software. 2003 Mar 20;20(2):66-71.

[15] Dawson-Maddocks, A., Cooper, D., \& Scobie, C. (1997). Operations and maintenance centre: Delivering network services. British Telecommunications Engineering 